\title{
Molecular epidemiology of coagulase-negative Staphylococcus carriage in neonates admitted to an intensive care unit in Brazil
}

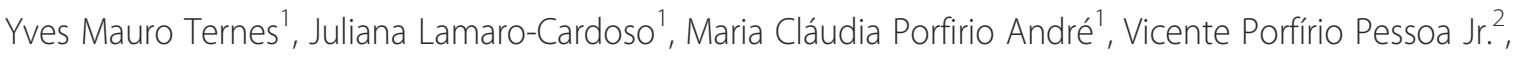 \\ Maria Aparecida da Silva Vieira ${ }^{3}$, Ruth Minamisava ${ }^{4}$, Ana Lúcia Andrade ${ }^{1}$ and André Kipnis ${ }^{1 *}$
}

\begin{abstract}
Background: Nasal colonization with coagulase-negative Staphylococcus (CoNS) has been described as a risk factor for subsequent systemic infection. In this study, we evaluated the genetic profile of CoNS isolates colonizing the nares of children admitted to a neonatal intensive care unit (NICU).

Methods: We assessed CoNS carriage at admittance and discharge among newborns admitted to a NICU from July 2007 through May 2008 in one of the major municipalities of Brazil. Isolates were screened on mannitol salt agar and tryptic soy broth and tested for susceptibility to antimicrobials using the disc diffusion method. Polymerase chain reaction (PCR) was used to determine the species, the presence of the mecA gene, and to perform SCCmec typing. S. epidermidis and S. haemolyticus isolated from the same child at both admission and discharge were characterized by PFGE.

Results: Among 429 neonates admitted to the NICU, 392 (91.4\%) had nasal swabs collected at both admission and discharge. The incidence of CoNS during the hospitalization period was 55.9\% (95\% confidence interval [Cl]: 50.960.7). The most frequently isolated species were S. haemolyticus (38.3\%) and S.epidermidis (38.0\%). Multidrug resistance (MDR) was detected in $2.2 \%$ and $29.9 \%$ of the CoNS isolates, respectively at admittance and discharge $(p=0.053)$. The mecA gene was more prevalent among strains isolated at discharge $(83.6 \%)$ than those isolated at admission (60\%); overall, SCCmec type I was isolated most frequently. The length of hospitalization was associated with colonization by MDR isolates $(p<0.005)$. Great genetic diversity was observed among $S$. epidermidis and S. haemolyticus.
\end{abstract}

Conclusions: NICU represents an environment of risk for colonization by MDR CoNS. Neonates admitted to the NICU can become a reservoir of CoNS strains with the potential to spread MDR strains into the community.

Keywords: Coagulase-negative Staphylococcus, mecA, SCCmec, Neonatal intensive care units, Neonates

\section{Background}

Coagulase-negative Staphylococcus (CoNS) are the most common bacteria associated with neonatal healthcareassociated infections [1]. Colonization with CoNS is a risk factor associated with infection among neonates [2]. The neonatal hospital population has several characteristics that favor the development of infections; primarily, these include the immature immune system of the neonates, the

\footnotetext{
* Correspondence: andre.kipnis@gmail.com

${ }^{1}$ Institute of Tropical Pathology and Public Health, Federal University of Goiás, Goiânia, GO, Brazil

Full list of author information is available at the end of the article
}

use of invasive procedures, and aggressive antibiotic therapy protocols $[3,4]$. Consequently, CoNS strains play an important role in the environment of neonatal intensive care units (NICUs) [5].

Rates of methicillin resistance up to $80 \%$ have been observed among CoNS isolated from bloodstream infections in NICU patients [1]. Resistance to other classes of antibiotics has also emerged in the last few decades $[6,7]$. S.epidermidis, considered as the main reservoirs for multidrug resistant (MDR), have been isolated from the skin of patients and health care staff, medical equipment, healthcare professionals' clothing, and hospital

\section{Biomed Central}

(C) 2013 Ternes et al.; licensee BioMed Central Ltd. This is an open access article distributed under the terms of the Creative Commons Attribution License (http://creativecommons.org/licenses/by/2.0), which permits unrestricted use, distribution, and reproduction in any medium, provided the original work is properly cited. 
surfaces [8]. S. epidermidis is the predominant CoNS species in infections associated with immune deficiency, catheters, and other invasive procedures [9,10]; in most cases, infection occurs due to migration of the microorganism from the skin to the vascular catheter insertion point, which favors hematogenic dissemination and infection [4].

Infections caused by CoNS are related to a significant increase in acute neonatal mortality; in some cases, they may be associated with the development of respiratory complications $[11,12]$. The identification of nasal colonization by CoNS could be useful for the prevention of future infections. [13].

Most of the studies on CoNS nasal colonization in neonates were conducted in the1990s [2] and showed a colonization prevalence ranging from $13 \%$ to $56 \%$ $[14,15]$. A recent study investigated early colonization by CoNS in 46 preterm neonates at the NICU and found that $55 \%$ of the neonates were colonized within the first 3 days of hospitalization [12].

In Latin America, information regarding the characteristics of CoNS carriage in neonates as well as the relationship between colonizing and invasive CoNS isolates is scarce [16]. In this study, we assessed different species of CoNS and antibiotic susceptibility of isolates colonizing the nares of children admitted to a NICU of a major city located in Central Brazil. Potential risk factors for colonization and the genetic relatedness among the CoNS strains isolated at admission and discharge were also evaluated.

\section{Methods}

\section{Patient enrollment and sample collection}

This prospective study was carried out from July 2007 through May 2008 in the NICU of Hospital da Criança (26 neonatal beds), located in Goiania $(\sim 1,300,000$ inhabitants). All children admitted to the NICU during the study period were eligible for nasal swab collection. The investigation was approved by the Regional Ethical Committee of Hospital Materno Infantil (CEP-HMI $\# 006 / 07$ ), and written consent was obtained from the neonates' parents. A nasal swab (Copan ${ }^{\circ}$ CA, USA) was collected from the neonates at admittance and discharge, and transported in Stuart's medium to the Microbiology Laboratory of the Federal University of Goiás.

\section{Risk factors}

Potential risk factors for CoNS colonization, which were obtained from medical records by physicians and nurses, included type of birth, sepsis occurrence, prematurity, age (days) at hospitalization, antimicrobial use during hospitalization, low birthweight, length of hospitalization (days), use of continuous positive airway pressure (CPAP), gender, and comorbidities (chronic, genetic, infectious diseases, and fetal malformation). The criteria for sepsis definition followed the Centers for Disease Control and Prevention (CDC) guidelines [17] with local adaptations.

\section{Microbiological procedures}

The nasal swabs were inoculated onto mannitol salt agar and one suggestive colony from each patient was submitted to screening tests. Each colony was identified by standard methods [18].

\section{Susceptibility tests}

CoNS isolates were submitted to a disk diffusion susceptibility test with the following antibiotics: oxacillin $(1 \mu \mathrm{g})$, cefoxitin $(30 \mu \mathrm{g})$, erythromycin $(15 \mu \mathrm{g})$, clindamycin $(2 \mu \mathrm{g})$, quinupristin-dalfopristin $(15 \mu \mathrm{g})$, rifampicin $(15 \mu \mathrm{g})$, ciprofloxacin $(5 \mu \mathrm{g})$, tetracycline $(30 \mu \mathrm{g})$, sulfamethoxazole-trimethoprim $(23.75 / 1.25 \mu \mathrm{g})$, linezolid $(30 \mu \mathrm{g})$, and penicillin $(10 \mu \mathrm{g})$ (Oxoid $^{\circ}$, Basingstoke, England). Inhibition halos were interpreted according to the Clinical Laboratory and Standards Institute (CLSI) guidelines [19]. The D test for macrolide-lincosamidestreptogramin B (MLSb) resistance was performed according to Fiebelkorn et al. [20]. Resistance to at least four classes of antibiotics was defined as MDR [21]. Vancomycin and teicoplanin susceptibilities were not tested.

\section{Identification of CoNS species}

DNA was extracted from the isolates identified as CoNS according to the method of van Embden et al. [22]. Internal transcribed spacer (ITS) PCR was performed according to Couto et al. [23] to identify the staphylococcal species. Reference strains for S. epidermidis (DEN125), $S$. haemolyticus (ICE145), S. warneri(DEN157), S. lugdunensis (ICE187), S. saprophyticus (DEN177), S. caprae (COB25), S. cohnii (ITL152), S. simulans (AGT121), and S. carnosus (TAW88) were kindly provided by Dr. Hermínia de Lencastre (Laboratory of Molecular Genetics, Institute for Chemical and Biological Technology, Nova Lisboa University, Oeiras, Portugal) and used as controls. The PCR product of each strain was compared to those of the reference strains. A species was assigned when a perfect match of the PCR products of a particular sample with that of the reference strain was obtained [23].

\section{SCCmec typing}

PCR was performed as previously described by Geha et al. [24] to ascertain the presence of the mecA gene for all CoNS strains. Staphylococcal cassette chromosome mec (SCCmec) typing was performed by multiplex PCR [25]. The regions identified were as follows: type I (J1 region); type II (J1 and J3 regions, ccr complex, and mec complex); type III (J1 and J3 regions and mec complex); 
type IV (J3 region and ccr complex); type V (J1 region and $c c r$ complex); and type VI (J3 region). PCR was performed in a thermocycler (Biocycler ${ }^{\circ}$, Zhejiang, China), and the PCR products were resolved by electrophoresis on a $1.5 \%$ agarose gel stained with ethidium bromide. A Gel Doc XR System (Bio-Rad ${ }^{\circ}$ Laboratories, Hercules, CA, USA) was used for visualization and analysis. The following Staphylococcus aureus strains (kindly provided by Dr. Herminia de Lencastre, ICBT, UNL, Oeiras, Portugal) were used as controls for SCCmec typing: COL (type I); N316 (type II); ANS46 (type III); MW2 (type IV); and WIS (type V). Strains harboring the mecA gene that did not produce amplification of any SCCmec gene were assigned as nontypeable (NT).

\section{Multilocus sequence typing (MLST) of Staphylococcus epidermidis}

Determination of MLST was performed by sequencing the PCR amplicons of the following housekeeping genes: shikimate dehydrogenase (aroE), carbamate kinase ( $\operatorname{arcC})$, $\mathrm{ABC}$ transporter (gtr), DNA mismatch repair protein (mutS), pyrimidine operon regulatory protein (pyrR), triphosphate isomerase (tpiA), and acetyl coenzyme A acetyltransferase $(y q i L)$. Primers used for amplification of the seven housekeeping genes were those recommended by the unified MLST scheme (http://sepidermidis.mlst.net/ misc/info.asp) that employs the internal fragments of $\operatorname{arcC}$ and aroE from the Wisplinghoffet al. MLST scheme [26], gtr, mutS and pyrR loci from the Thomas et al. MLST scheme [27] and sequences from the tpiA and yqiL genes used by the Wang et al. MLST scheme [28]. Sequencing of purified amplicons was performed on an ABI $3130 \mathrm{XL}$ genetic analyzer (Applied Biosystems, Foster City, CA, USA). Sequences obtained were assigned allele numbers that were used to generate sequence types (STs) for each isolate.

\section{Pulsed field gel electrophoresis (PFGE) analysis}

The genetic relatedness of the most prevalent species $(S$. epidermidis and $S$. haemolyticus) was determined by PFGE according to Chung et al. [29]. Band patterns were interpreted based on the criteria described by Tenover et al. [30], and analyses were performed using BioNumerics software version 5.0 (Applied Maths, Kortriik, Belgium). The resulting dendrogram was constructed using the unweighted pair group method for arithmetic averages and the Dice band-based similarity coefficient. Isolates were defined as epidemiologically related (same cluster) if they shared $\geq 80 \%$ similarity on the dendrogram [31].

\section{Data analysis}

All data were analyzed with SPSS ${ }^{\circ}$ software version 18.0 (Chicago, USA). Neonates carrying CoNS at admission were removed from the analysis for incidence rate calculations. The susceptibility profiles of the isolates at admission and discharge were analyzed to evaluate the progression of drug resistance among CoNS during the period of hospitalization. Univariate analyses were performed with the Chi-square and Mann-Whitney tests, and relative risk for MDR CoNS carriage, with the respective $95 \%$ confidence intervals $(95 \% \mathrm{CI})$, was calculated. Odds ratio and 95\% CI was used in multiple logistic regression model to measure the effect of the exposure variables on MDR CoNS carriage using backward stepwise elimination. The Hosmer-Lemeshow statistical test was used to determine the goodness-of-fit of the logistic regression model. P-values less than 0.05 were considered significant for all analyses.

\section{Results}

A total of 429 neonates were admitted to the NICU during the study period. Nasal swabs were collected from 392 (91.4\%) neonates at both admission and discharge. The frequency of nasal carriage by CoNS was $69.9 \%$ (95\% confidence interval [CI]: 65.2-74.3). The incidence of colonization by CoNS in the neonatal cohort during the hospitalization period was $55.9 \%$ (95\% CI: 50.9-60.7).

The antibiotics associated with MDR were oxacillin/ cefoxitin, erythromycin, clindamycin, ciprofloxacin, tetracycline, and sulfamethoxazole-trimethoprim. There was a significant increase in the frequency of MDR CoNS isolates at discharge compared with the frequency at admission (29.9\% and $2.2 \%$, respectively, $\mathrm{p}=0.053$ ). The frequencies of resistance to all antimicrobials tested, except for tetracycline, were higher among the CoNS isolated at discharge compared with the CoNS isolated at admission. Tetracycline resistance decreased among the CoNS from admission to discharge. Nasal carriage of MDR CoNS was significantly associated with length of hospitalization (Figure 1).

The prevalence of $\beta$-lactam antibiotic (cefoxitin and oxacillin) resistance among 45 CoNS isolates at admission was $57.8 \%$ and increased to $89.3 \%$ among 244 isolates at discharge $(\mathrm{p}=0.165)$; two neonates were colonized by CoNS with a MLSb-resistant phenotype (one at admission and one at discharge). The mecA gene was detected at frequencies of $60.0 \%$ and $83.6 \%$ at admission and at discharge, respectively. Antimicrobial susceptibility for isolates from twenty-four children was not performed due to failure to recover viable culture. The frequencies of the mecA gene and bacterial resistance among CoNS isolates were higher $(\mathrm{p}=0.296)$ at discharge compared with admission (Table 1).

SCCmec typing revealed similar frequencies of types I, and IV at both admission and discharge. Types I, II, and III accounted for the majority of SCCmec identified in this study. Several CoNS isolates presented more than one SCCmec type $45.8 \%$ of the isolates from admission and $46.5 \%$ from discharge) (Table 2 and Additional file 1: Table S1). 


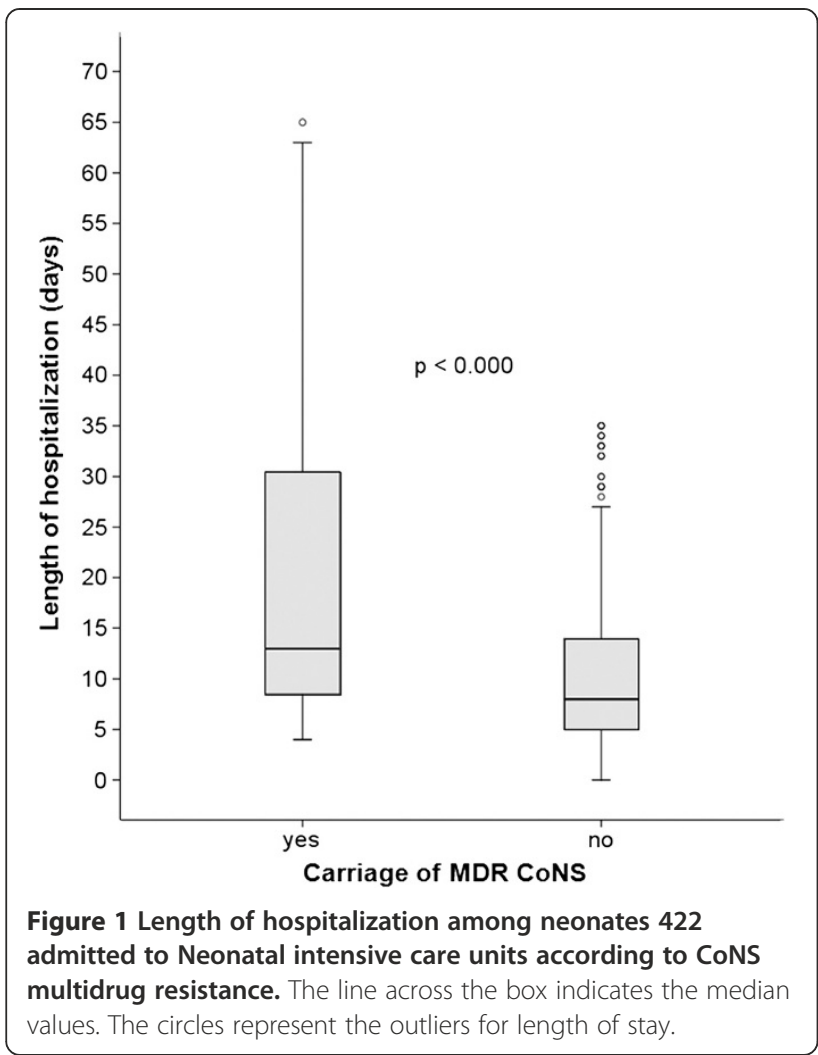

S. epidermidis (38.3\%) and S. haemolyticus (38.0\%) were the most frequent species colonizing the neonates followed by S. capitis (4.7\%), S. warneri (4.4\%), S. kloosii (1.4\%), S. caprae (1.4\%), S. schleiferi (1.1\%), S. hominis (0.7\%), S. lugdunensis (0.7\%), and S. saprophyticus (0.4\%). $S$. epidermidis was primarily observed at admission,

Table 1 Cefoxitin resistance and presence of the mecA gene among CoNS nasal isolates obtained from neonates in the NICU at admission and discharge from July 2007 through May 2008

\begin{tabular}{|c|c|c|c|c|}
\hline \multirow[t]{3}{*}{ Variables } & \multicolumn{4}{|c|}{ Coagulase-negative Staphylococcus isolates } \\
\hline & \multicolumn{2}{|c|}{ Admission $(\mathrm{N}=45)$} & \multicolumn{2}{|c|}{ Discharge $(\mathrm{N}=244)$} \\
\hline & $\mathbf{n}$ & $\%$ & $\mathbf{N}$ & $\%$ \\
\hline \multicolumn{5}{|l|}{ Cefoxitin } \\
\hline Resistant & 26 & 57.8 & 218 & 89.3 \\
\hline Susceptible & 19 & 42.2 & 26 & 10.7 \\
\hline \multicolumn{5}{|l|}{ mecA genotype } \\
\hline Positive & 27 & 60.0 & 204 & 83.6 \\
\hline Negative & 18 & 40.0 & 40 & 16.4 \\
\hline \multicolumn{5}{|c|}{ Multidrug resistance $^{a}$} \\
\hline Yes & 1 & 2.2 & 73 & 29.9 \\
\hline No & 44 & 97.8 & 171 & 70.1 \\
\hline
\end{tabular}

${ }^{a}$ Multidrug resistance was considered as resistance to at least four classes of antibiotics. whereas S. haemolyticus predominated at discharge. Twenty-four isolates (8.2\%) showed ITS-PCR patterns that differed from those of the reference strains and could therefore not be assigned to a species.

The persistence of the same strain within a particular individual during the hospitalization period was evaluated by PFGE for S. epidermidis and S. haemolyticus, which were the most prevalent species isolated in this study. S. epidermidis was isolated from eight patients and S. haemolyticus was isolated from four patients at both admission and discharge, and the PFGE dendrogram revealed significant genetic diversity between the strains (Figures 2 and 3). Two patients (\#507 and \#119) were colonized by the same $S$. epidermidis clone during their entire hospitalization period. One patient (\#608) presented strains with a mixed SCCmec type (III/IV) at both admission and discharge despite the low similarity $(<50 \%)$ between them. Only one patient (\#584) was persistently colonized by the same $S$. haemolyticus clone, which can be explained by the short duration of hospitalization (one day). Two patients (\#779-discharge, \#585-admission) presented strains with different SCCmec types (III and I, respectively) despite the high similarity (>90\%) between them. Among the studied risk factors, the length of hospitalization was the only significant variable $(p<0.001)$ associated with MDR CoNS colonization (Table 3).

The molecular characterization of eight $S$. epidermidis strains representatives of different PFGE patterns by MLST identified 7 STs. Two strains were assigned as ST 59 , one as ST 81 and one as ST 86, while the other four strains were assigned new STs based on their allelic profiles and were single-locus variants (SLV) of STs 21, 130, 158,291, 351, 450, or 466 (Additional file 2: Table S2 and Additional file 3: Figure S1). The observed STs are included in the major clonal complex (CC2) of the $S$. epidermidis lineages.

\section{Discussion}

Few investigations have been performed to examine CoNS neonatal colonization in NICU settings. We observed a lower incidence of CoNS colonization in neonates during hospitalization (55.9\%) compared with Campeotto et al. [32], who observed a $66.1 \%$ incidence of colonization in nasal specimens from children admitted to the NICU. However, we collected samples only at admittance and discharge, whereas the cited study sampled the children weekly.

We found that the prevalence of MDR was increased among CoNS strains isolated at discharge, which could most likely be explained by the intensive selective pressure caused by antibiotic therapy administered to patients admitted to the NICU, as reported by others [33]. The increase of MDR prevalence could not be explained 
Table 2 SCCmec frequencies at admission and discharge, among the most prevalent mecA containing strains isolated from neonates from July 2007 through May 2008

\begin{tabular}{|c|c|c|c|c|c|c|c|c|}
\hline \multirow[t]{2}{*}{ SCCmec type } & \multicolumn{2}{|c|}{ S. epidermidis (\%) } & \multicolumn{2}{|c|}{ S. haemolyticus (\%) } & \multicolumn{2}{|c|}{ S. capitis (\%) } & \multicolumn{2}{|c|}{ S. warneri (\%) } \\
\hline & Adm* & Disch $^{* *}$ & Adm & Disch & Adm & Disch & Adm & Disch \\
\hline I & $1(8.3)$ & $7(9.6)$ & $3(25.0)$ & $56(68.3)$ & 0 & 0 & 0 & $1(50)$ \\
\hline II & 0 & $1(1.4)$ & 0 & 0 & 0 & 0 & 0 & 0 \\
\hline III & 0 & $4(5.5)$ & $1(8.3)$ & $1(1.2)$ & 0 & $2(11.8)$ & 0 & 0 \\
\hline IV & $3(25.0)$ & $9(12.3)$ & 0 & $1(1.2)$ & 0 & 0 & 0 & 0 \\
\hline v & $1(8.3)$ & $1(1.4)$ & 0 & 0 & 0 & 0 & 0 & 0 \\
\hline 2 types & $4(33.3)$ & $35(47.9)$ & $2(16.7)$ & 7 (8.6) & 0 & $15(88.2)$ & 0 & 0 \\
\hline 3 or more & $1(8.3)$ & $12(16.4)$ & $4(33.3)$ & $11(13.4)$ & 0 & 0 & 0 & 0 \\
\hline Non typeable & $2(16.8)$ & $4(5.1)$ & $2(16,7)$ & $6(7.3)$ & 0 & 0 & 0 & $1(50)$ \\
\hline Total & 12 & 73 & 12 & 82 & 0 & 17 & 0 & 2 \\
\hline
\end{tabular}

*Adm: Admission.

**Disch: Discharge.

***Nontypeable: Defined as strains harboring the mecA gene, that did not produce amplification of any SCCmec gene.

by an increase in frequency of colonization by S. haemolyticus alone, as susceptibility profile of $S$. haemolyticus isolated at admission showed that they were as susceptible as other species (data not shown). We also detected a high rate of antimicrobial resistance to $\beta$-lactam antibiotics (oxacillin and cefoxitin), which is conferred by the $m e c$ A gene. Similar to our results, studies of colonization and sepsis among hospitalized neonates have reported that most CoNS species carry the mecA gene and that microorganisms isolated from systemic diseases have even higher resistance rates $[1,34]$. Taken together, these observations support the hypothesis that CoNS may be a genetic repository of antibiotic resistance genes, particularly mecA, and may serve as a carrier and/or reservoir of antibiotic resistance, which increases the risk of staphylococcal infection in the hospital environment [35]. In Brazil, the use of tetracycline in pediatrics is very limited, which may explain the lower prevalence of tetracycline resistance among CoNS isolated at discharge in our findings.

\begin{tabular}{|c|c|c|c|c|c|}
\hline 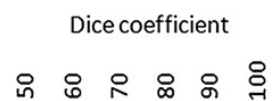 & S. epidermidis & ID & $A / D$ & $\mathrm{sccmec}$ & $\begin{array}{l}\text { Length of } \\
\text { hospitalization } \\
\text { (days) }\end{array}$ \\
\hline & & $420 *$ & D & - & 6 \\
\hline & & 665 & D & - & 6 \\
\hline & & 724 & A & I, III & 6 \\
\hline & & 608 & D & III, IV & 5 \\
\hline & & 507 & A & NT & 9 \\
\hline & & 507 & $\mathrm{D}$ & II, IV & 9 \\
\hline & & 119 & A & IV & 14 \\
\hline & & $119 *$ & $D$ & IV, V & 14 \\
\hline & & 502 & A & NT & 4 \\
\hline & & 420 & A & III, IV & 6 \\
\hline & & $502 *$ & D & NT & 4 \\
\hline & & 723 & A & 1 & 24 \\
\hline & ] & 723 & $\mathrm{D}$ & - & 24 \\
\hline & & 665 & A & IV & 6 \\
\hline & & 608 & A & III, IV & 5 \\
\hline & & 724 & $\mathrm{D}$ & 1 & 6 \\
\hline
\end{tabular}




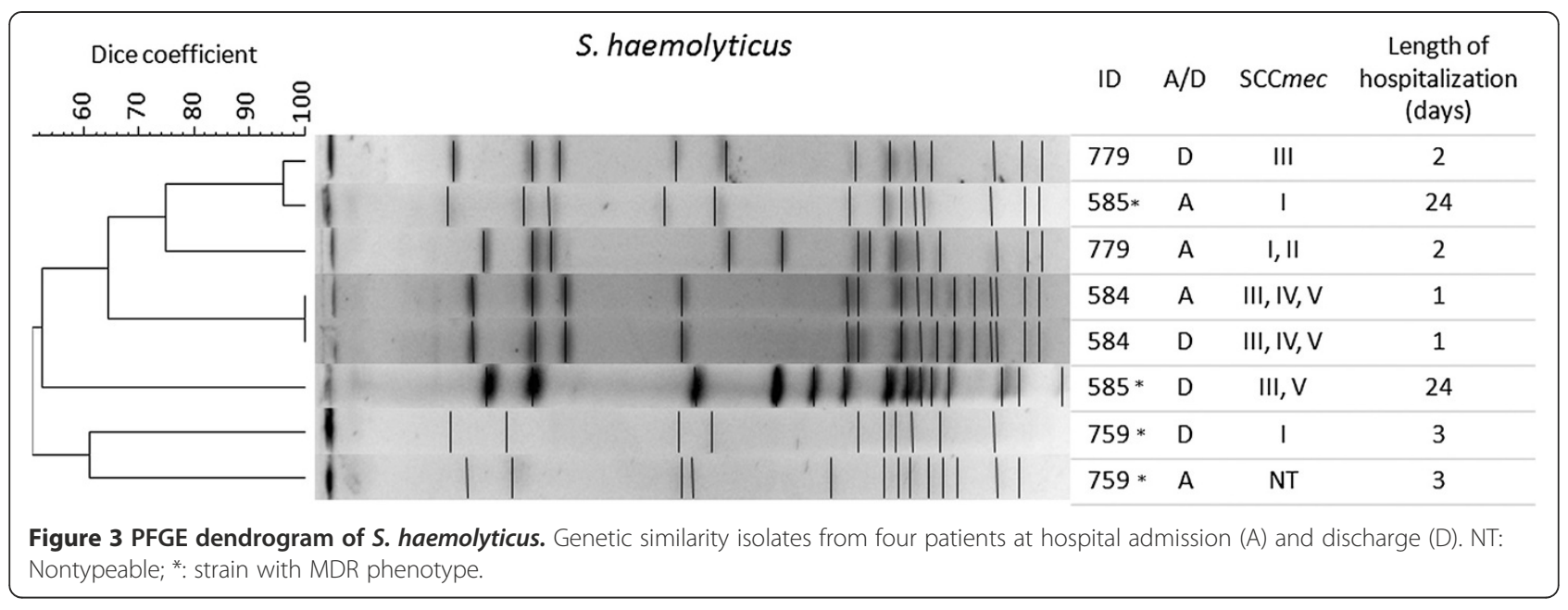

Studies have shown that the frequency of SCCmec among CoNS is increasing due to the wide dissemination of the microorganism in hospital-acquired infections, which is associated with the potential genetic transfer of resistance elements among Staphylococcus spp. [36]. We observed a high frequency (86.7\%) of SCCmec types I, II, and III among CoNS isolates at discharge (considering isolates with only one SCCmec type). Similar SCCmec type frequencies were observed among CoNS isolated from blood culture of patients

Table 3 Risk factors for multidrug resistance in CoNS isolates among children admitted to the NICU in Brazil from July 2007 through May 2008

\begin{tabular}{|c|c|c|c|c|c|c|c|c|}
\hline \multirow[t]{2}{*}{ Variables } & \multicolumn{2}{|c|}{ Incident cases of MDR CoNS ${ }^{a}$} & \multirow[t]{2}{*}{ RR } & \multirow[t]{2}{*}{$95 \% \mathrm{Cl}$} & \multirow[t]{2}{*}{$P$ value } & \multirow[t]{2}{*}{$O R^{b}$} & \multirow[t]{2}{*}{$95 \% \mathrm{Cl}$} & \multirow[t]{2}{*}{$P$ value } \\
\hline & Yes & No & & & & & & \\
\hline \multicolumn{9}{|l|}{ Sex } \\
\hline Male & 46 & 184 & 1.29 & $0.80-2.34$ & 0.256 & & & \\
\hline Female & 25 & 136 & & & & & & \\
\hline \multicolumn{9}{|l|}{ Antimicrobial use } \\
\hline Yes & 62 & 241 & 2.42 & $1.10-5.37$ & 0.011 & 0.51 & $0.21-1.26$ & 0.144 \\
\hline No & 6 & 65 & & & & & & \\
\hline \multicolumn{9}{|l|}{ Low birthweight } \\
\hline Yes & 43 & 162 & 1.26 & $0.88-2.09$ & 0.162 & & & \\
\hline No & 28 & 153 & & & & & & \\
\hline \multicolumn{9}{|l|}{ Age at hospitalization } \\
\hline$<24$ hours & 55 & 241 & 1.12 & $0.67-1.85$ & 0.670 & & & \\
\hline$\geq 24$ hours & 16 & 80 & & & & & & \\
\hline \multicolumn{9}{|l|}{ Type of birth } \\
\hline Caesarean & 39 & 219 & 0.61 & $0.40-0.93$ & 0.023 & 1.70 & $0.97-2.99$ & 0.064 \\
\hline Vaginal & 32 & 97 & & & & & & \\
\hline \multicolumn{9}{|l|}{ CPAPC } \\
\hline Yes & 30 & 97 & 1.53 & $1.00-2.35$ & 0.056 & 1.08 & $0.58-2.03$ & 0.805 \\
\hline No & 38 & 208 & & & & & & \\
\hline \multicolumn{9}{|l|}{ Hospitalization ${ }^{d}$} \\
\hline Median & 9 & 2 & & & $<0.05$ & 0.97 & $0.96-0.98$ & 0.000 \\
\hline Interquartile range & $5-15$ & $2-2$ & & & & & & \\
\hline
\end{tabular}

${ }^{a}$ Multidrug-resistant (resistance to four or more classes of antimicrobials), coagulase-negative Staphylococcus.

bodds Ratio adjusted for age at hospitalization and sex.

${ }^{\mathrm{C}}$ Continuous positive airway pressure.

${ }^{d}$ Length of hospitalization (days). 
attending a tertiary hospital in southern Brazil [37]. Data regarding SCCmec typing of CoNS carriage among neonates are scarce in the literature, and caution must be taken when making comparisons of our findings. These types are commonly related with healthcare-associated methicillin-resistant Staphylococcus aureus (MRSA) [38], although it is not clear what SCCmec types are associated with particular CoNS species. Although CoNS isolates often present SCCmec types similar to those of $S$. aureus, they may also present unique, complex groups of SCCmecs [13], thereby acting as reservoirs for particular SCCmec genes and elements. The diverse SCCmec type profile among CoNS strains, as described previously [39], is due to the higher capacity for genetic transfer between the species. In addition, CoNS strains present a combination of SCCmec types, with SCCmec type IV being most frequently associated with other types of chromosomal cassettes. Due to the various combinations of different SCCmec types in the CoNS observed here and reported by others [40,41], there is aclear need to develop a unique typing system for this group of bacteria.

Although S. epidermidis has been reported as the most frequent CoNS species colonizing neonates, the most prevalent CoNS species colonizing the neonates at discharge in our study was S. haemolyticus. This observation could be related to the ability of $S$. haemolyticus to adapt to selective pressures, such as antimicrobials and biocides present in the hospital environment $[8,42]$.

The high degree of genetic diversity among CoNS, as revealed by PFGE, and the presence of different SCCmec types at both admittance and discharge suggest that nasal colonization by these species is a very dynamic process in the NICU environment. Although a neonate is typically admitted to the hospital with a particular strain of S. epidermidis, there is a high probability that the nasal colonization will be replaced by a Staphylococcus species that is highly drug resistant and likely acquired from the hospital environment or professional staff [13]. The length of hospitalization could be associated with MDR CoNS, as a longer stay would result in greater exposure to these factors.

Although there are scarce data regarding CoNS colonization, blood culture-positive newborns have been associated with CoNS colonization [12]. Further studies are needed to address the effect of colonization with MDR CoNS on infection among neonates that are admitted to intensive care and undergo invasive procedures.

The identification of a single genetic lineage (CC2) comprising the majority of STs was showed worldwide [10]. The CC2 is considered the most prevalent complex in the nosocomial population of S. epidermidis and has been characterized by a high level of genetic diversity, an increased recombination/mutation rate, and a high number of SCCmec elements $[10,43]$ as demonstrated in this study.

The present study has some limitations. Ideally, several nasal swabs should be collected during the neonatal hospitalization period to assess the dynamic characteristics of CoNS carriage status. Additionally, the currently available techniques for SCCmec characterization of CoNS are based on the $S$. aureus prototype. The SCCmec typing method used in this study is limited to the identification of certain region combinations, mainly $\mathrm{J}$ regions. It would be desirable to use entire nucleotide sequence to ascertain SCCmec elements and avoid possible misclassification [44].

\section{Conclusion}

We have shown that children admitted to the NICU have a high rate of nasal colonization by CoNS with an increased frequency of MDR strains during the hospitalization period, primarily at discharge. In addition, we observed a high rate of $\mathrm{SCCmec}$ dissemination in the healthcare environment. An extended stay in the NICU could result in a greater risk for neonate colonization by MDR CoNS strains and consequently an increased risk of systemic infection by these microorganisms.

\section{Additional files}

Additional file 1: Table S1. SCCmec types and frequencies at admission and discharges among strains with more than one type isolated from neonates from July 2007 through May 2008.

Additional file 2: Table S2. MLST analysis from eight S. epidermidis strains isolated from neonates in this study. Sequencing analysis of each locus resulted in an allele determination. Based on the allelic profile for each sample, exact or approximate sequence types (STs) were assigned.

Additional file 3: Figure S1. Dendrogram based on MLST from eight $S$. epidermidis samples. Samples identification numbers preceded by UFG are samples isolated in this study. Samples preceded by ST are from MLST database (http://sepidermidis.mlst.net/sql/download_st.asp).

\section{Competing interests}

The authors declare that they have no competing interests.

\section{Authors' contributions}

ALA and AK participated on the conception and design of the study, analysis and interpretation of data and drafting the manuscript. YMT and JLC participated in acquisition of data, molecular tests, interpreting results and revised the manuscript. MCPA participated in acquisition of data, molecular tests, and critically contributed to the draft of the manuscript. VPPJ and MASV participated in patients' recruitment, supervision of all epidemiological data collection, interpretation of data and revising the manuscript. RM contributed on the study design, analysis and interpretation of epidemiological data, managing the database, and critically revised the manuscript. All authors read and approved the final version of the manuscript.

\section{Acknowledgements}

This investigation received support from the National Council of Technological and Scientific Development (CNPq). We are grateful to the Hospital da Criança, Goiânia-GO-Brasil, for technical assistance with sample collection and patients. We thank Copan Diagnostics Inc. for swab donation. ALA (306096/2010-2) and AK (301198/2009-8) are recipients of a fellowship from CNPq. 


\section{Author details}

${ }^{1}$ Institute of Tropical Pathology and Public Health, Federal University of Goiás, Goiânia, GO, Brazil. ²Children's Hospital, Goiânia, Brazil. ${ }^{3}$ Pontifical Catholic University of Goiás, Goiânia, GO, Brazil. ${ }^{4}$ School of Nursing, Federal University of Goiás, Goiânia, GO, Brazil.

Received: 2 June 2013 Accepted: 26 November 2013

Published: 5 December 2013

\section{References}

1. Hira V, Sluijter M, Estevao S, Horst-Kreft D, Ott A, de Groot R, Hermans PW Kornelisse RF: Clinical and molecular epidemiologic characteristics of coagulase-negative staphylococcal bloodstream infections in intensive care neonates. Pediatr Infect Dis J 2007, 26(7):607-612.

2. D'Angio CT, McGowan KL, Baumgart S, St Geme J, Harris MC: Surface colonization with coagulase-negative staphylococci in premature neonates. J Pediatr 1989, 114(6):1029-1034.

3. Srivastava S, Shetty N: Healthcare-associated infections in neonatal units: lessons from contrasting worlds. J Hosp Infect 2007, 65(4):292-306.

4. Walz JM, Memtsoudis SG, Heard SO: Prevention of central venous catheter bloodstream infections. J Intensive Care Med 2010, 25(3):131-138.

5. Cheung GY, Otto M: Understanding the significance of Staphylococcus epidermidis bacteremia in babies and children. Curr Opin Infect Dis 2010, 23(3):208-216

6. Cercenado E: Update of antimicrobial resistance in Gram-positive microorganisms. Med Clin (Barc) 2010, 135(Suppl 3):10-15.

7. Sharma P, Lahiri KK, Kapila K: Conventional and molecular characterization of coagulase-negative Staphylococcus in hospital isolates. Indian J Pathol Microbiol 2011, 54(1):85-89.

8. Aires De Sousa M, Santos Sanches I, Ferro ML, De Lencastre $\mathrm{H}$ : Epidemiological study of staphylococcal colonization and cross-infection in two West African Hospitals. Microb Drug Resist 2000, 6(2):133-141.

9. de Mattos EM, Teixeira LA, Alves VM, Rezenda e Resende CA, da Silva Coimbra MV, da Silva-Carvalho MC, Ferreira-Carvalho BT, Figueiredo AM: Isolation of methicillin-resistant coagulase-negative staphylococci from patients undergoing continuous ambulatory peritoneal dialysis (CAPD) and comparison of different molecular techniques for discriminating isolates of Staphylococcus epidermidis. Diagn Microbiol Infect Dis 2003, 45(1):13-22.

10. Miragaia M, Thomas JC, Couto I, Enright MC, de Lencastre H: Inferring a population structure for Staphylococcus epidermidis from multilocus sequence typing data. J Bacteriol 2007, 189(6):2540-2552.

11. Liljedahl M, Bodin L, Schollin J: Coagulase-negative staphylococcal sepsis as a predictor of bronchopulmonary dysplasia. Acta Paediatr 2004, 93(2):211-215

12. Bjorkqvist M, Liljedahl M, Zimmermann J, Schollin J, Soderquist B: Colonization pattern of coagulase-negative staphylococci in preterm neonates and the relation to bacteremia. Eur J Clin Microbiol Infect Dis 2010, 29(9):1085-1093.

13. Jamaluddin TZ, Kuwahara-Arai K, Hisata K, Terasawa M, Cui L, Baba T, Sotozono C, Kinoshita S, Ito T, Hiramatsu K: Extreme genetic diversity of methicillin-resistant Staphylococcus epidermidis strains disseminated among healthy Japanese children. J Clin Microbiol 2008, 46(11):3778-3783.

14. Hall SL, Riddell SW, Barnes WG, Meng L, Hall RT: Evaluation of coagulasenegative staphylococcal isolates from serial nasopharyngeal cultures of premature infants. Diagn Microbiol Infect Dis 1990, 13(1):17-23.

15. Mehta G, Singh S, Kumari S: Observations on coagulase-negative staphylococci in a neonatal unit in India. J Hosp Infect 1991, 19(4):273-281.

16. Pessoa-Silva CL, Richtmann R, Calil R, Santos RM, Costa ML, Frota AC, Wey SB: Healthcare-associated infections among neonates in Brazil. Infect Control Hosp Epidemiol 2004, 25(9):772-777.

17. Garner JS, Jarvis WR, Emori TG, Horan TC, Hughes JM: CDC definitions for nosocomial infections, 1988. Am J Infect Control 1988, 16(3):128-140.

18. Freney J, Kloos WE, Hajek V, Webster JA, Bes M, Brun Y, Vernozy-Rozand C Recommended minimal standards for description of new staphylococcal species. Subcommittee on the taxonomy of staphylococci and streptococci of the International Committee on Systematic Bacteriology. Int J Syst Bacteriol 1999, 49(Pt 2):489-502.

19. Clinical and Laboratory Standards Institute: Performance standards for antimicrobial susceptibility testing; eighteenth informational supplement, M100S18. Wayne, PA: Clinical and Laboratory Standards Institute (CLSI); 2008.
20. Fiebelkorn KR, Crawford SA, McElmeel ML, Jorgensen JH: Practical disk diffusion method for detection of inducible clindamycin resistance in Staphylococcus aureus and coagulase-negative staphylococci. J Clin Microbiol 2003, 41(10):4740-4744.

21. Agvald-Ohman C, Lund B, Edlund C: Multiresistant coagulase-negative staphylococci disseminate frequently between intubated patients in a multidisciplinary intensive care unit. Crit Care 2004, 8(1):R42-47.

22. van Embden JD, Cave MD, Crawford JT, Dale JW, Eisenach KD, Gicquel B, Hermans P, Martin C, McAdam R, Shinnick TM, et al: Strain identification of Mycobacterium tuberculosis by DNA fingerprinting: recommendations for a standardized methodology. J Clin Microbiol 1993, 31(2):406-409.

23. Couto I, Pereira S, Miragaia M, Sanches IS, de Lencastre H: Identification of clinical staphylococcal isolates from humans by internal transcribed spacer PCR. J Clin Microbiol 2001, 39(9):3099-3103.

24. Geha DJ, Uhl JR, Gustaferro CA, Persing DH: Multiplex PCR for identification of methicillin-resistant staphylococci in the clinical laboratory. J Clin Microbiol 1994, 32(7):1768-1772.

25. Milheirico C, Oliveira DC, de Lencastre H: Update to the multiplex PCR strategy for assignment of mec element types in Staphylococcus aureus. Antimicrob Agents Chemother 2007, 51(9):3374-3377.

26. Wisplinghoff $\mathrm{H}$, Rosato AE, Enright MC, Noto M, Craig W, Archer GL: Related clones containing SCCmec type IV predominate among clinically significant Staphylococcus epidermidis isolates. Antimicrob Agents Chemother 2003, 47(11):3574-3579.

27. Thomas JC, Vargas MR, Miragaia M, Peacock SJ, Archer GL, Enright MC Improved multilocus sequence typing scheme for Staphylococcus epidermidis. J Clin Microbiol 2007, 45(2):616-619.

28. Wang XM, Noble L, Kreiswirth BN, Eisner W, McClements W, Jansen KU, Anderson AS: Evaluation of a multilocus sequence typing system for Staphylococcus epidermidis. J Med Microbiol 2003, 52(Pt 11):989-998.

29. Chung $M$, de Lencastre $H$, Matthews $P$, Tomasz A, Adamsson I, Aires de Sousa M, Camou T, Cocuzza C, Corso A, Couto l, et al: Molecular typing of methicillin-resistant Staphylococcus aureus by pulsed-field ge electrophoresis: comparison of results obtained in a multilaboratory effort using identical protocols and MRSA strains. Microb Drug Resist 2000, 6(3):189-198.

30. Tenover FC, Arbeit RD, Goering RV, Mickelsen PA, Murray BE, Persing DH Swaminathan B: Interpreting chromosomal DNA restriction patterns produced by pulsed-field gel electrophoresis: criteria for bacterial strain typing. J Clin Microbiol 1995, 33(9):2233-2239.

31. Tenover FC, Arbeit RD, Goering RV: How to select and interpret molecular strain typing methods for epidemiological studies of bacterial infections: a review for healthcare epidemiologists. Molecular Typing Working Group of the Society for Healthcare Epidemiology of America. Infect Control Hosp Epidemiol 1997, 18(6):426-439.

32. Campeotto F, Garnier F, Kalach N, Soulaines P, Dupont C, Raymond J: A routine prospective survey process to detect nosocomial bacterial colonization in a neonatal unit: risk factors for acquisition. Arch Pediat 2004, 11(11):1314-1318.

33. Klingenberg C, Aarag E, Ronnestad A, Sollid JE, Abrahamsen TG, Kjeldsen G, Flaegstad T: Coagulase-negative staphylococcal sepsis in neonates. Association between antibiotic resistance, biofilm formation and the host inflammatory response. Pediatr Infect Dis J 2005, 24(9):817-822.

34. Krediet TG, Jones ME, Janssen K, Gerards $L$, Fleer A: Prevalence of molecular types and mecA gene carriage of coagulase-negative Staphylococci in a neonatal intensive care unit: relation to nosocomial septicemia. J Clin Microbiol 2001, 39(9):3376-3378.

35. Mongkolrattanothai K, Boyle S, Kahana MD, Daum RS: Severe Staphylococcus aureus infections caused by clonally related communityacquired methicillin-susceptible and methicillin-resistant isolates. Clin Infect Dis 2003, 37(8):1050-1058

36. Chlebowicz MA, Nganou K, Kozytska S, Arends JP, Engelmann S, Grundmann H, Ohlsen K, van Dijl JM, Buist G: Recombination between ccrC genes in a type V (5C2\&5) staphylococcal cassette chromosome mec (SCCmec) of Staphylococcus aureus ST398 leads to conversion from methicillin resistance to methicillin susceptibility in vivo. Antimicrob Agents Chemother 2010, 54(2):783-791.

37. Mombach Pinheiro Machado AB, Reiter KC, Paiva RM, Barth AL: Distribution of staphylococcal cassette chromosome mec (SCCmec) types I, II, III and IV in coagulase-negative staphylococci from patients attending a tertiary hospital in southern Brazil. J Med Microbiol 2007, 56(10):1328-1333. 
38. Barbier F, Ruppe E, Hernandez D, Lebeaux D, Francois P, Felix B, Desprez A Maiga A, Woerther PL, Gaillard K, et al: Methicillin-resistant coagulasenegative staphylococci in the community: high homology of SCCmec IVa between Staphylococcus epidermidis and major clones of methicillinresistant Staphylococcus aureus. J Infect Dis 2010, 202(2):270-281.

39. Zhang Y, Agidi S, LeJeune JT: Diversity of staphylococcal cassette chromosome in coagulase-negative staphylococci from animal sources. J Appl Microbiol 2009, 107(4):1375-1383.

40. Urushibara N, Paul SK, Hossain MA, Kawaguchiya M, Kobayashi N: Analysis of Staphylococcal cassette chromosome mec in Staphylococcus haemolyticus and Staphylococcus sciuri: identification of a novel ccr gene complex with a newly identified ccrA allotype (ccrA7). Microb Drug Resist 2011, 17(2):291-297.

41. Zong Z, Peng C, Lu X: Diversity of SCCmec elements in methicillinresistant coagulase-negative staphylococci clinical isolates. PLoS One 2011, 6(5):e20191.

42. Ben Saida N, Marzouk M, Ferjeni A, Boukadida J: A three-year surveillance of nosocomial infections by methicillin-resistant Staphylococcus haemolyticus in newborns reveals the disinfectant as a possible reservoir. Pathol Biol (Paris) 2009, 57(3):e29-35.

43. Du X, Zhu Y, Song Y, Li T, Luo T, Sun G, Yang C, Cao C, Lu Y, Li M: Molecular analysis of Staphylococcus epidermidis strains isolated from community and hospital environments in China. PLoS One 2013, 8(5):e62742.

44. International Working Group on the Classification of Staphylococcal Cassette Chromosome Elements: Classification of staphylococcal cassette chromosome mec ( $\mathrm{SCCmec}$ ): guidelines for reporting novel $\mathrm{SCCmec}$ elements. Antimicrob Agents Chemother 2009, 53(12):4961-4967.

doi:10.1186/1471-2334-13-572

Cite this article as: Ternes et al:: Molecular epidemiology of coagulasenegative Staphylococcus carriage in neonates admitted to an intensive care unit in Brazil. BMC Infectious Diseases 2013 13:572.

\section{Submit your next manuscript to BioMed Central and take full advantage of:}

- Convenient online submission

- Thorough peer review

- No space constraints or color figure charges

- Immediate publication on acceptance

- Inclusion in PubMed, CAS, Scopus and Google Scholar

- Research which is freely available for redistribution 